Editorial

\title{
Home- and Community-Based Work at the Margins of Welfare: Balancing between Disciplinary, Participatory and Caring Approaches
}

\author{
Kirsi Juhila ${ }^{1, *}$, Cecilia Hansen Löfstrand ${ }^{2}$ and Johanna Ranta ${ }^{1}$ \\ ${ }^{1}$ Faculty of Social Sciences, Tampere University, Finland; E-Mail: kirsi.juhila@tuni.fi (K.J.), johanna.ranta@tuni.fi (J.R) \\ ${ }^{2}$ Department of Sociology and Work Science, University of Gothenburg, Sweden; E-Mail: cecilia.lofstrand@gu.se \\ * Corresponding author
}

Submitted: 6 July 2021 | Published: 26 August 2021

\begin{abstract}
By the end of the 20th century, deinstitutionalisation had become a pervasive trend in the Western world. This thematic issue discusses how successful deinstitutionalisation has been in enabling dignified and safe living with necessary services in local communities. It contributes to an understanding of the history and phases of deinstitutionalisation and 'home turn' policies, and sheds light on the grassroots-level of home- and community-based work at the margins of welfare, hitherto little researched. The latter includes grassroots work to implement the Housing First approach to homelessness, commonly portrayed as a means of social inclusion, worker-client interactions during home visits and in the local community, as well as close inspections of what 'housing support' may actually entail in terms of care, discipline and service user participation.
\end{abstract}

\section{Keywords}

deinstitutionalisation; grassroots level; home turn; Housing First; participation; worker-client interaction

\section{Issue}

This editorial is part of the issue "Home- and Community-Based Work at the Margins of Welfare: Balancing between Disciplinary, Participatory and Caring Approaches" edited by Kirsi Juhila (Tampere University, Finland), Cecilia Hansen Löfstrand (University of Gothenburg, Sweden) and Johanna Ranta (Tampere University, Finland).

(C) 2021 by the authors; licensee Cogitatio (Lisbon, Portugal). This editorial is licensed under a Creative Commons Attribution 4.0 International License (CC BY).

\section{Introduction}

Deinstitutionalisation, meaning "the complete replacement of institutions by services in the community" (Mansell, 2005, p. 26), is seen as a human rights issue and has become a pervasive trend in the Western world. Large treatment institutions have been depicted as typical examples of what Goffman refers to as "total institutions" (Goffman, 1961, p. xiii), i.e., "a place of residence and work where a large number of like-situated individuals, cut off from the wider society for an appreciable period of time, together lead an enclosed, formally administered round of life." Institutions have been argued as being stigmatising, violating clients' and patients' privacy and free lives, and segregating them from what is culturally defined as 'normal' living in the community. Based on such arguments, different types of community services have developed over time (see Hall et al., 2021).
The first phase of deinstitutionalisation, starting approximately $40-50$ years ago, included creating various group and residential homes for people who had previously lived in large total institutions. During the last decades, providing services in people's own homes and local communities has been on the increase. This 'home turn,' resulting from the second phase of deinstitutionalisation, emphasises that everyone is entitled to their own affordable and safe home place in the community regardless of economic status, possible problems or support needs. However, it is not always clear what it actually means to offer welfare services in communities and homes nor the kinds of dilemmas and tensions it may include.

This thematic issue discusses how successful deinstitutionalisation has been in enabling dignified and safe living with necessary services in the community. The special focus is on grassroots level home- and 
community-based work at the margins of welfare. By this, we mean work targeted at adults with complex needs, suffering, for example, from mental health and substance abuse problems, and homelessness. Despite being motivated to promote human rights, this type of work can include many contradictions. In practice, the work means balancing between disciplinary, participatory and caring approaches, such as surveilling home environments and making pedagogical interventions on home lives, attempting to engage people with the wider community and prevent isolation, and ensuring people's safe and decent lives.

\section{Deinstitutionalisation: Back and Forth}

The article by Hall et al. (2021) is based on a literature review of research published from 1990 onwards about deinstitutionalisation and 'home turn' policies. It discusses and evaluates thoroughly the two abovementioned policy phases (phase one of group or residential homes and phase two of home-based services) regarding vulnerable adults' care in in the community. They focus especially on how these policies are argued to both promote and hamper social inclusion and, thus, community participation in the Western world. The main conclusion is that the aim of social inclusion has not yet been fulfilled, although steps taken towards 'home turn' have advanced this.

Urek (2021) continues the evaluation of the history of deinstitutionalisation by describing its process in Slovenian mental health services since the 1980s. She concentrates on services users' roles in the process. By using multiple types of data, the author demonstrates how the history includes some innovative participatory practices, but also a large gap between the declarative participation policy and lived participation experiences. Both Hall et al. (2021) and Urek (2021) importantly remark that large institutions still exist and, furthermore, that 'institution-like' practices, including a disciplinary orientation towards service users, may have been transferred to residential and group homes and even home spaces (transinstitutionalisation and reinstitutionalisation).

Using a multiple-case study design that includes five Swedish municipalities, Fjellfeldt et al. (2021) investigate efforts to find suitable locations for supported housing units for people with severe mental illness, while also shedding light on community resistance towards the establishment of group or residential homes in their communities. In their article, the authors identify three municipal strategies-using existing buildings for a new purpose, infilling new buildings in existing neighbourhoods and establishing new buildings in a new area. Taken together, however, all three strategies tend to result in residential homes being established in the outskirts (geographical margins) of local communities. Arguably, homes in the 'fringes' of local communities may hamper the goal of social inclusion.

\section{Efforts towards 'Housing First'}

Several of the thematic issue's articles explore the role of Housing First policy in community- and home-based service practices. Housing First emphasises everyone's right to their own apartment without any conditions, such as abstinence, and housing independent from the services provided. It thus questions the tradition of institutions, including various shelters, residential and group homes, in which housing, treatment, care and control are merged. As Housing First prioritises community-living in scattered site housing, it aligns with the premises of social inclusion and participation. Housing First can be seen as an example of 'home turn'; according to its principles, homelessness shelters, which carry many of the criticised features of institutions such as discipline and control of residents, should be shut down. Instead, homeless people should be given individual accommodation with their own rental agreements. This change also entails identity transformation and struggles among both workers and clients, as Hansen Löfstrand and Juhila (2021) show in their article. Based on a mobile ethnographic study in Sweden, the article includes both focus group interviews with workers and observations of worker-client interactions during home visits.

In Finland, Housing First is commonly implemented in congregated housing units besides in individual apartments on the regular housing market (as in Sweden). In the congregated housing units, making a distinction between housing and services is difficult, and residents may not feel that their accommodation is their own home space. Workers in the units can take a caring but sometimes a controlling or even disciplinary orientation towards residents. This becomes evident in Granfelt and Turunen (2021), when they analyse interviews with workers in one such unit. However, using another type of data consisting of interviews with women living in Housing First scattered-site rental flats, Granfelt and Turunen (2021) demonstrate the successful pathways to living in an accommodation that feels like one's home and increases participation in the community. The important element in these success stories is trust-based relationships with social and care workers in the women's past and present lives.

In Knutagård et al. (2021), transformation towards Housing First philosophy in social housing programmes is examined from the viewpoints of service user involvement and strength perspective (cf. Urek, 2021). They ask how service users participate and are encouraged to participate in the process of change in social housing programmes. Drawing on multiple data sources, their participatory action research focuses especially on participation-enabling niches in the process. An important conclusion is that enabling niches are more difficult to sustain in congregate housing units than in Housing First-oriented programmes; having one's own apartment in the community creates an enabling niche in itself. Knutagård et al. (2021) also emphasise social workers' 
important role in discovering and supporting 'missing heroes,' who would be willing and competent to participate in coproducing change. Trust between parties in co-producing change is also emphasised.

\section{Worker-Client Interactions in Homes and Communities}

Taken together, as illustrated above, meaningful and trust-based relationships between service users and social and care workers as well as service user participation as an enabling resource in home-based services are deemed important by scholars. Three of the issue's articles illuminate the characteristics of these relationships, as they analyse in detail real-life worker-client interactions in service users' homes and nearby communities. Holmberg and Räsänen (2021) disclose how floating support encounters with clients suffering from mental health and substance abuse problems include emotionally loaded conversations on being and moving in the community outside the home. It demonstrates how workers can support clients' inclusion and participation in nearby neighbourhoods and decrease their risk of isolation.

Günther (2021) reveals how intimate worker-client interactions can be during home visits. Body work includes talk not only about clients' physical health and problems, but also actions entailing direct physical contact between workers and clients, such as showering. It further illustrates that entering clients' private homes and conducting body work have both caring and disciplinary dimensions, which creates a risk of homes becoming institutionalised. However, conducting body work can also strengthen clients' participation if it is based on their own wishes and on trustful relationships between workers and clients.

Entering private home spaces is also in focus in Saario et al. (2021). They analyse how workers justify the continuation or termination of support to mental health clients defined as difficult to reach in their homes, although home visiting is scheduled and included in their care plans. The balance between disciplinary and caring actions is strongly present in their analysis, and it is connected to workers' ethical responsibilities. Ceasing to support 'hard-to-reach' clients can be interpreted as disciplinary action, but so can continuation, if the clients themselves resist home visits. However, continuing support can also be seen as a sign of caring; clients are not left on their own if they are assessed as needing help.

\section{What is Community- and Home-Based Work About?}

Results of the studies described above demonstrate that community- and home-based work in times of deinstitutionalisation and 'home turn' is manifold and entails balancing between disciplinary, participatory and caring approaches. Three of the remaining articles discuss the sometimes unclear and contextually changing nature of this work. Börjesson et al. (2021) draw on the concept of institutional logic to understand the variations of housing support in mental health in different municipalities in a Swedish county. The analysis of focus group interviews with care managers, managers of home- and community-based support, and housing support workers shows that the meaning of housing support is constructed through dichotomies of process and product, independence and dependence, and flexibility and structure. These dichotomies create space for professional discretion as no clear guidelines for housing support exist.

Carlsson Stylianides et al. (2021) offer another viewpoint on the contents of housing support. Based on their analysis of interviews with staff from municipal social services and the municipal housing company, they argue that the housing company has increasingly started to deny some people the right to housing. These people are then referred to social services, who thus carry the risk of possible failures in housing. This produces categorical inequality and increases the number of people whose housing is controlled by social workers via contracts and weekly inspections during home visits. This work is not based on the wishes or needs of the people in need of housing, but on the preferences and risk-minimisation strategies of municipal housing companies.

\section{Acknowledgments}

Publication of this thematic issue was made possible by the Academy of Finland funding of the research project "Geographies of Home-based Service Interactions at the Margins of Welfare in Finland and Sweden" (GEOHOME, decision number 307661).

\section{Conflict of Interests}

The authors declare no conflict of interests.

\section{References}

Börjesson, U., Skillmark, M., Bülow, P. H., Bülow, P., Vejklint, M., \& Wilińska, M. (2021). "It's about living like everyone else": Dichotomies of housing support in Swedish mental health care. Social Inclusion, 9(3), 276-285.

Carlsson Stylianides, K., Denvall, V., \& Knutagård, M. (2021). Durable homelessness: From negotiations to emulation. Social Inclusion, 9(3), 286-295.

Fjellfeldt, M., Högström, E., Berglund-Snodgrass, L., \& Markström, U. (2021). Title pending final manuscript. Social Inclusion, 9(3), 201-213.

Goffman, E. (1961). Asylums. Doubleday; Anchor.

Granfelt, R., \& Turunen, S. (2021). Women on the border between home and homelessness: Analysing worker-client relationship. Social Inclusion, 9(3), 223-233.

Günther, K. (2021). Body work in home-based substance abuse care. Social Inclusion, 9(3), 256-264. 
Hall, C., Raitakari, S., \& Juhila, K. (2021). Deinstitutionalisation and 'home turn' policies: Promoting or hampering social inclusion? Social Inclusion, 9(3), 179-189.

Hansen Löfstrand, C., \& Juhila, K. (2021). Transforming worker-client identities: From shelters to Housing First. Social Inclusion, 9(3), 214-222.

Holmberg, S., \& Räsänen, J.-M. (2021). From home to community: Reflecting emotions related to mobility. Social Inclusion, 9(3), 245-255.

Knutagård, M., Heule, C., \& Kristiansen, A. (2021). Missing hero: Co-producing change in social housing pro- grammes. Social Inclusion, 9(3), 234-244.

Mansell, J. (2005). Deinstitutionalisation and community living: An international perspective. Tizard Learning Disability Review, 10(1), 22-29.

Saario, S., Hall, C., \& Lydahl, D. (2021). Engaging with hard-to-reach clients: Towards the last resort response by welfare workers. Social Inclusion, 9(3), 265-275.

Urek, M. (2021). The right to 'have a say' in the deinstitutionalisation of mental health in Slovenia. Social Inclusion, 9(3), 190-200.

\section{About the Authors}

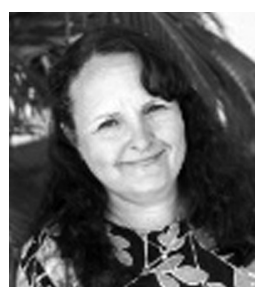

Kirsi Juhila is Professor in social work at the Faculty of Social Sciences, Tampere University, Finland. Her research interests include institutional interaction in social welfare settings and the issues of user participation, social exclusion, marginalisation and homelessness. She has methodological expertise in discourse analytic approaches. She is a member of Margi Research Group, and currently leads research projects concentrating on home visit interactions at the margins of welfare and on the processes of forced relocation of public housing residents.

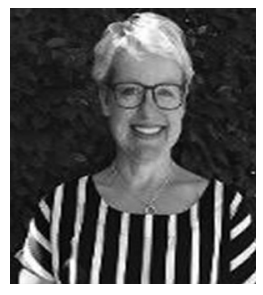

Cecilia Hansen Löfstrand is Associate Professor of sociology and senior lecturer in sociology, at the Department of Sociology and Work Science, University of Gothenburg, Sweden. Her competence includes sociology, criminology, and victimology, and she has headed and collaborated on research projects concerning the margins of welfare society and its services, victimology, public, private, and voluntary policing as well as policing partnerships. She currently leads a research project on security officers' use of body-worn cameras in the private security industry.

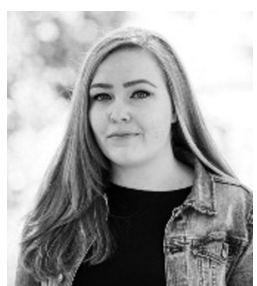

Johanna Ranta is a Postdoctoral Researcher in social work at the Faculty of Social Sciences, Tampere University, Finland. Her methodological interests include discursive methods and mobile ethnography, which she has applied in her doctoral dissertation and in the projects of the Margi Research Group, with a particular focus on homelessness and home-based services at the margins of welfare. Her current ethnographic postdoc research project concentrates on outreach work encounters with people using illicit drugs. 